\title{
A resposta do setor de saneamento no Brasil à COVID-19
}

\author{
Morganna Werneck Capodeferro 12 \\ Juliana Jerônimo Smiderle 13 \\ 1 Fundação Getulio Vargas / Centro de Estudos em Regulação e Infraestrutura, Rio de Janeiro / RJ - Brasil \\ 2 Universidade Federal do Rio de Janeiro / Programa de Engenharia Civil, Rio de Janeiro / RJ - Brasil \\ 3 Universidade Federal do Rio de Janeiro / Programa de Engenharia Ambiental, Rio de Janeiro / RJ - Brasil
}

\begin{abstract}
A essencialidade da água à vida talvez tenha ficado ainda mais evidente com a pandemia da COVID-19. Aos prestadores dos serviços de saneamento foi atribuída a responsabilidade de garantir à população a manutenção do abastecimento de água potável, fornecendo meios para que ela pudesse preservar os hábitos de higiene e controlar a propagação do vírus. No entanto, como se poderia garantir que a prestação do serviço não fosse afetada, seja pelo acometimento dos funcionários, seja pela reduzida capacidade de pagamento dos usuários? Este foi o desafio enfrentado pelos prestadores. Diversas foram as medidas adotadas pela Administração Pública para responder no curto prazo a esse desafio, tais como: restrição ao atendimento presencial nas unidades, isenção tarifária aos usuários da tarifa social e suspensão do corte por inadimplência. Contudo todas estas medidas podem desequilibrar as contas dos prestadores de serviço, deixando-os em uma situação de instabilidade que, a princípio, deverá ser sustentada até o fim da pandemia, quando os processos de reequilíbrio econômico-financeiro serão conduzidos pelos reguladores. Estes são e continuarão sendo os principais atores na minimização dos impactos que incidiram sobre os prestadores e na mediação das negociações futuras. Este artigo traz recomendações aos reguladores sobre como tratar os desequilíbrios causados pela pandemia nos futuros processos. Caberá aos reguladores emitir diretrizes claras com relação ao procedimento a ser adotado pelos prestadores, para que possam pleitear o reequilíbrio de suas contas. Deve-se cogitar neste momento a flexibilização das metas contratuais.
\end{abstract}

Palavras-chave: COVID-19; água e saneamento; desequilíbrio econômico-financeiro; regulação.

\section{La respuesta del sector de saneamiento en Brasil a la COVID-19}

Talvez, la esencialidad del agua para la vida se ha hecho aún más evidente con la pandemia de COVID-19. Los proveedores de servicios de saneamiento tuvieron la responsabilidad de mantener el suministro de agua potable para proporcionarle a la población los medios para mantener sus hábitos de higiene y controlar la propagación del virus. Pero, ¿cómo podría garantizarse que la prestación del servicio no se vería afectada, sea por la disminución de empleados o la capacidad de pago reducida de los usuarios? Este fue el desafío planteado a los proveedores. La Administración Pública tomó varias medidas para responder rápidamente a este desafío. Las iniciativas más adoptadas fueron la restricción del servicio presencial, la exención de tarifas para los usuarios vulnerables socioeconómicamente y la suspensión del corte por incumplimiento. El hecho es que todas las medidas pueden desequilibrar las cuentas de los proveedores de servicios, dejándolos en una situación de inestabilidad que, en principio, debería mantenerse hasta el final de la pandemia, cuando los reguladores llevarán a cabo los procesos de reequilibrio económico y financiero. Los reguladores son y serán los principales actores para minimizar los impactos en los proveedores y mediar en las negociaciones futuras. Este artículo proporciona recomendaciones a los reguladores sobre cómo abordar los desequilibrios causados por la pandemia en procesos futuros. Competirá a los reguladores emitir pautas claras con respecto al procedimiento que adoptarán los proveedores para que puedan reclamar el reequilibrio de sus cuentas. En este momento, se debe considerar la flexibilización de los objetivos contractuales.

Palabras clave: COVID-19; agua y saneamiento; desequilibrio económico y financiero; regulación. 


\section{The Brazilian sanitation sector's response to COVID-19}

The COVID-19 pandemic has evidenced the essentiality of water more prominently. Service providers were responsible for maintaining drinking water supply to the population to maintain good hygiene habits and control the spread of the virus. However, the challenge for providers was guaranteeing the service would not be affected, either by employees falling ill or by users unable to pay for the service provision. Public administration adopted several measures to respond in the short term to this challenge. The actions most frequently observed were the restriction of in-person services, payment exemption for vulnerable users, and suspension of procedures against non-payment. The measures may have unbalanced the accounts of the service providers, leaving them in a situation of instability that, in principle, should be sustained until the end of the pandemic, when the regulators will conduct the process to re-establishing the financial balance. The regulators are and will be the main actors in minimizing the impacts on providers and in mediating future negotiations. This article provides recommendations to regulators on how to address the imbalances caused by the pandemic in future processes. Regulators will have to issue clear guidelines regarding the procedures that providers will adopt to rebalance their accounts. Consideration should be given at this time to making contractual targets more flexible.

Keywords: COVID-19; water and sanitation; economic and financial imbalance; regulation.

\section{INTRODUÇÃO}

A pandemia da COVID-19 trouxe desafios jamais enfrentados pela Administração Pública, dentre os quais destaca-se a manutenção do fornecimento de serviços essenciais à população, como energia elétrica, telecomunicações e saneamento. A Organização Mundial da Saúde (OMS), desde o início da pandemia, publica orientações técnicas a serem seguidas pelos países no enfrentamento da nova doença. Uma das principais orientações - recomendada em todas as situações para reduzir a velocidade de transmissão do vírus - refere-se à manutenção de bons hábitos de higiene; dentre eles, lavar as mãos com água e sabão frequentemente (OMS, 2020). Parece algo simples e básico, mas infelizmente não é. De acordo com dados mais recentes do Fundo das Nações Unidas para a Infância e da Organização Mundial da Saúde (UNICEF \& OMS, 2019), 40\% da população mundial (3 bilhões de pessoas) não possuíam instalações básicas para lavagem das mãos em suas residências em 2017. No caso específico do Brasil, 33 milhões de brasileiros não recebem água encanada em suas residências (Ministério do Desenvolvimento Regional [MDR], 2018).

Somado a isto, artigo recentemente publicado por Wu et al. (2020) sugere a possibilidade da presença do novo coronavírus nas fezes de pacientes por quase cinco semanas após testes respiratórios terem resultado negativo. Yeo, Kaushal, e Yeo (2020) enunciaram esta hipótese, uma vez que os vírus do SARS-CoV e MERS-CoV, dois tipos de coronavírus já conhecidos, foram identificados nos esgotos em condições que facilitavam a transmissão feco-oral. Esses mesmos autores pontuam que a possibilidade deste tipo de transmissão da COVID-19 tem severas implicações, especialmente em áreas com falta de saneamento. Esta é a situação de 4,2 bilhões de pessoas no mundo (UNICEF \& OMS, 2019) e de 95 milhões de brasileiros que carecem de acesso à rede coletora de esgotos (MDR, 2018). Além disso, no Brasil menos da metade dos esgotos coletados são encaminhados para tratamento (MDR, 2018).

A fim de manter bons hábitos de higiene, a orientação da OMS que vem sendo adotada por diversos países é de garantir o abastecimento de água potável para a população. Neste cenário, surgem algumas perguntas. Como os atores deste setor estão garantindo a manutenção dos serviços, com a devida proteção de seus funcionários, para uma população que alterou o seu padrão de consumo e 
que teve sua capacidade de pagamento reduzida? Quais os impactos em curto, médio e longo prazo das medidas adotadas para manutenção do acesso à água sobre os diversos stakeholders? Como a Administração Pública deve responder a fim de minimizar os referidos impactos negativos? Estas são as questões que este artigo visa responder para o contexto brasileiro.

Para tanto, o artigo descreve, inicialmente, a prestação dos serviços de saneamento no Brasil; em seguida, são apresentadas as respostas imediatas adotadas pela Administração Pública diante do desafio imposto pela pandemia, tendo como foco as ações que afetaram as 26 Companhias Estaduais de Saneamento Básico (CESBs); os impactos decorrentes das medidas são identificados e segregados entre prestadores de serviço, usuários e reguladores. Com base nesta análise, foram formuladas recomendações a serem seguidas pela Administração Pública em virtude dos impactos negativos.

\section{A PRESTAÇÃO DOS SERVIÇOS DE SANEAMENTO NO BRASIL}

Tendo em vista as ações e os impactos das medidas de prevenção à COVID-19 sobre as prestadoras de saneamento no Brasil, busca-se compreender, preliminarmente, a estrutura do setor de saneamento do país. Segundo o entendimento do Supremo Tribunal Federal, os municípios são os responsáveis pelos serviços de saneamento no Brasil - titulares dos serviços - e podem prestá-los diretamente ou delegá-los a terceiros. A prestação direta ocorre em 22\% dos municípios (MDR, 2018), já dentre os que delegam a execução do serviço, 96\% são atendidos pelas CESBs. Os demais têm os serviços prestados pela iniciativa privada. A Figura 1 apresenta a porcentagem da população atendida por cada tipo de prestador.

\section{FIGURA 1 PORCENTAGEM DA POPULAÇÃO ATENDIDA POR TIPO DE PRESTADOR}

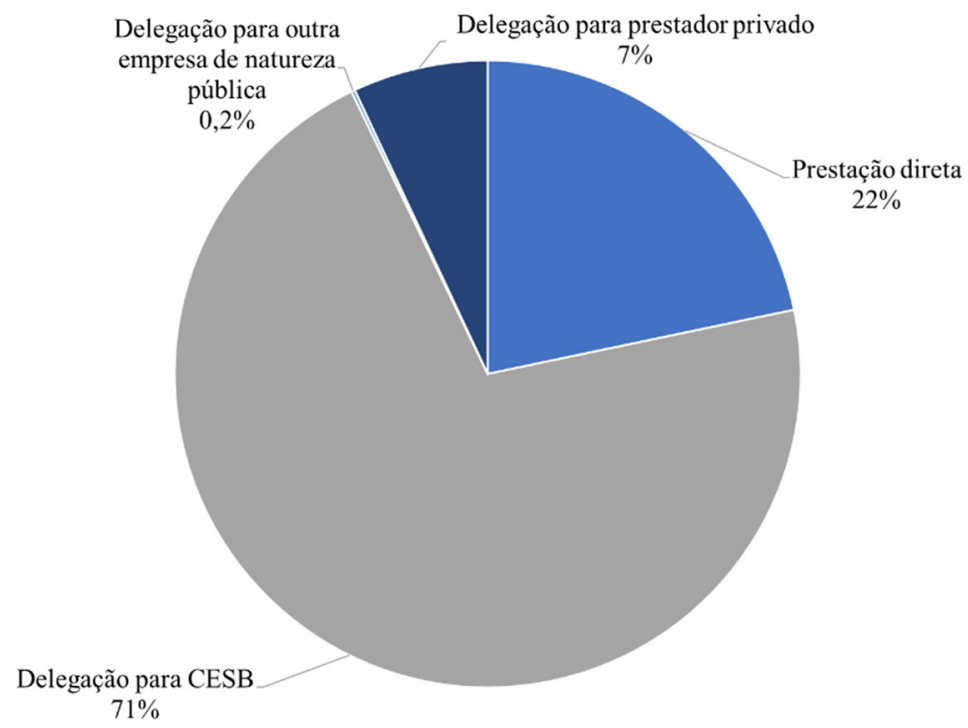

Fonte: MDR (2018). 
A prestação dos serviços de saneamento se estruturou e se concentrou em torno das CESBs (Smiderle, Capodeferro, Fernandes, Gonçalves, \& Dutra, 2020), que são, majoritariamente, empresas públicas; das 26 CESBs atualmente existentes no país, apenas uma é de controle privado. Portanto verifica-se grande participação dos estados no setor, apesar de a titularidade ser municipal.

A razão pela qual a estruturação do setor se deu por meio de companhias estaduais foi a possibilidade que esse arranjo oferecia de viabilizar economicamente a prestação do serviço. As CESBs continuam a atuar em um conjunto de munícipios de um mesmo estado, os quais, com poucas variações, adotam uma estrutura tarifária única e praticam o subsídio cruzado, seja entre municípios superavitários e deficitários ou mesmo entre diferentes classes de consumidores. Em geral, a estrutura tarifária é dividida em categorias de usuários (residencial, comercial, industrial e pública) e em blocos de consumo. O subsídio entre classes de consumidores costuma se dar entre usuários não residenciais e residenciais; os últimos pagam tarifas menores comparativamente às categorias comercial, industrial e pública.

\section{RESPOSTAS IMEDIATAS DA ADMINISTRAÇÃO PÚBLICA}

Desde o diagnóstico dos primeiros casos da COVID-19 no país, muitos estados brasileiros decretaram medidas de distanciamento social, ou quarentena, e estabeleceram o fechamento do comércio e a paralisação dos serviços não essenciais. Estas medidas são suficientes para causar um forte impacto na atividade econômica e nos níveis de desemprego.

Neste contexto, os prestadores de serviço de saneamento se viram diante do desafio de manter o abastecimento de água potável, tão necessário à prevenção da doença, para uma população com reduzida capacidade de pagamento. Imediatamente, os atores do setor (titulares do serviço, prestadores e reguladores) encadearam uma série de ações voltadas tanto para a proteção dos funcionários das prestadoras responsáveis pelos serviços, quanto dos usuários, em especial dos financeiramente mais vulneráveis.

Neste artigo, investigam-se as ações adotadas pelas CESBs em atendimento às determinações dos seus respectivos governos estaduais e reguladores. Dentre as ações analisadas, destacam-se: (i) mudança na forma de faturamento; (ii) restrição do atendimento presencial; (iii) adiamento da aplicação dos reajustes tarifários; (iv) facilitação do pagamento das tarifas de água e esgotos; (v) isenção tarifária para usuários vulneráveis; e (vi) suspensão do corte por inadimplência.

Com relação à proteção dos funcionários, identificou-se a adoção de medidas visando à redução da exposição dos funcionários e, consequentemente, dos próprios usuários. Algumas companhias determinaram que o faturamento considerasse valores médios dos históricos de consumo em substituição à leitura dos hidrômetros, a exemplo da Companhia de Saneamento Ambiental do Distrito Federal (Caesb) - por meio da Resolução ADASA n. 03 (2020) -, da Companhia de Saneamento de Minas Gerais (Copasa, 2020a) e da Companhia Riograndense de Saneamento (Corsan, 2020). Uma alternativa criada pela Copasa foi a possibilidade de o próprio usuário efetuar a leitura de seu hidrômetro e informar à empresa; neste caso, o consumo faturado continua a ser pelo hidrômetro, e não pela média (Copasa, 2020b). Além disso, a maioria das companhias suspendeu ou restringiu seus atendimentos presenciais, disponibilizando canais virtuais para o atendimento de seus clientes.

No que tange às medidas de proteção dos usuários, o adiamento da aplicação dos reajustes tarifários foi determinado a fim de não sobreonerar as tarifas em tempos de retração econômica. Tal

ReVISTA DE AdMinistração PÚblica | Rio de Janeiro 54(4):1022-1036, jul. - ago. 2020 
medida foi adotada no estado do Paraná, por determinação da agência reguladora, que "congelou" as tarifas de todos os serviços regulados (Agência Reguladora do Paraná [Agepar], 2020), bem como no estado do Sergipe, por decisão do Governo de Sergipe (2020), e no Distrito Federal, por meio da Resolução ADASA n. 03 (2020).

Inúmeras medidas foram adotadas a fim de facilitar o pagamento. A dilatação do prazo para o pagamento das faturas de água e esgoto foi uma das mais adotadas, tendo sido anunciada, por exemplo, pela Copasa (2020a) e pela Companhia do Estado do Paraná (Sanepar). No caso da companhia paranaense, houve o adiamento da cobrança por 90 dias apenas para os usuários que pagam a tarifa social (Sanepar, 2020).

Outras facilidades de pagamento incluem a possibilidade de parcelamento dos valores cobrados, como na campanha de renegociação de débitos em atraso conduzida pela Companhia de Águas e Esgotos do Rio Grande do Norte (Caern, 2020). Para algumas companhias estaduais, como a Copasa e a Cosama, do Estado do Amazonas, determinou-se também a suspensão da cobrança de juros e multas decorrentes do atraso no pagamento pelos usuários que se enquadram na tarifa social, no primeiro caso (Copasa, 2020a), e de usuários em geral, no segundo caso (Governo do Amazonas, 2020).

A isenção tarifária foi concedida à categoria residencial social por inúmeras companhias, dentre elas a Companhia Espírito Santense de Saneamento (Cesan, 2020), a Companhia de Saneamento Básico do Estado de São Paulo (Sabesp) (Deliberação ARSESP n. 979, 2020) e a Companhia Estadual de Águas e Esgotos do Rio de Janeiro (CEDAE, 2020). A CEDAE acatou a determinação do Decreto Estadual n. 46.990 (2020), que facultava a isenção de clientes enquadrados na tarifa social e na categoria comércio de pequeno porte.

Complementarmente à isenção tarifária, determinou-se a suspensão do corte do fornecimento de água por inadimplência. Dentre os governos estaduais que decretaram tal medida, destacam-se o de Goiás (Governo de Goiás, 2020), o de Tocantins (Agência Tocantinense de Saneamento, 2020), o de Santa Catarina (Governo de Santa Catarina, 2020) e o de Rondônia (Agência Reguladora de Serviços Públicos Delegados do Estado de Rondônia [AGERO], 2020).

A Figura 2 apresenta o resultado do levantamento da adoção, por parte das CESBs, de cada uma das medidas apresentadas, que podem ter sido determinadas ou pelo próprio prestador, ou pelos governos estaduais ou reguladores, conforme descreve o texto. Para proteção dos funcionários, destaca-se, como medida adotada pelo maior número de companhias (88\%), a restrição aos atendimentos presenciais, e para proteção dos usuários, a suspensão do corte do fornecimento por $88 \%$ das companhias estaduais - medida determinante na garantia da continuidade dos serviços a todos.

Apesar de a análise aqui apresentada ter se restringido às CESBs, por sua representatividade para os estados e por atenderem a 70\% dos municípios brasileiros (MDR, 2018), as medidas foram também adotadas pelas demais prestadoras de saneamento, sem abrangência regional, como as empresas privadas ou serviços autônomos de água e esgotos municipais (SAAEs). Este é o caso, por exemplo, das empresas privadas e dos SAAEs regulados pela Agência Reguladora dos Serviços de Saneamento das Bacias dos Rios Piracicaba, Capivari e Jundiaí (ARES PCJ), conforme Resolução ARES-PCJ n. 345 (2020); da concessionária privada Saneaqua Mairinque S/A, regulada pela Agência Reguladora de Saneamento e Energia do Estado de São Paulo (ARSESP), conforme Deliberação ARSESP n. 978 (2020); e da Iguá Saneamento (2020), por determinação da própria empresa. 


\section{FIGURA 2 ADESÃO DENTRE AS 26 CESBS A CADA UMA DAS MEDIDAS PARA MANUTENÇÃO DA} PRESTAÇÃO DOS SERVIÇOS DURANTE A PANDEMIA

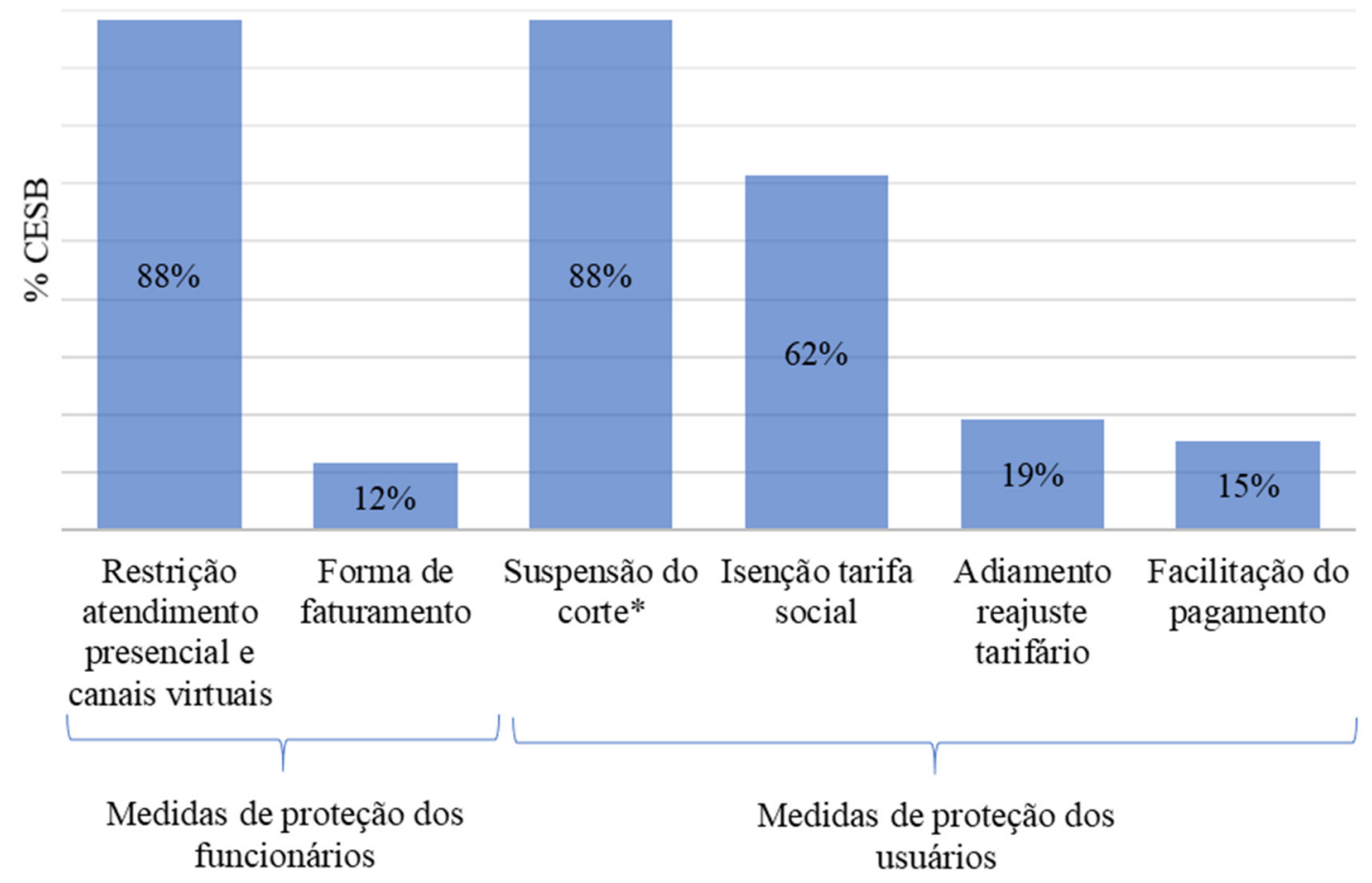

* Em quatro estados (MG, BA, PB e SP), o corte por inadimplência foi suspenso apenas para os usuários enquadrados na tarifa social, nos demais essa medida vale para todos os usuários.

Fonte: Elaborada pelos autores.

Reportando-se à forma como o setor de saneamento tem respondido ao desafio da pandemia internacionalmente, nota-se certo grau de alinhamento das medidas adotadas no Brasil. Muitas das ações voltadas à proteção dos usuários vão ao encontro das orientações do regulador dos serviços de água e esgoto do Reino Unido, Office of Water (Ofwat). A Ofwat é tida como um benchmark internacional em regulação, possui uma rica, longa e forte atuação no setor de saneamento, devido ao pioneirismo inglês na privatização da prestação deste serviço ainda na década de 70 (NH Consultoria e Planejamento, 1995). No enfrentamento da pandemia, a Ofwat solicitou às empresas que dessem suporte aos usuários vulneráveis, indicando que elas considerassem a possibilidade de reduzir a sobrecarga financeira sobre essas famílias, ou pelo aumento da assistência financeira (tarifa social) ou pela flexibilização dos pagamentos e cobranças de dívidas (Ofwat, 2020).

Outro benchmark internacional de destaque é o da Colômbia, cujo arranjo setorial, semelhante ao do Brasil, comporta a prestação predominantemente pública dos serviços - $80 \%$ dos municípios são atendidos por prestadoras públicas ou pelo próprio município (Ministério das Cidades, 2018). A regulação colombiana, no entanto, ao contrário da realidade brasileira, mostra ter avançado bastante e está atualmente em sua terceira fase de implantação, contando com um regulador nacional que edita diretrizes para aplicação local (Centro de Estudos de Regulação e Infraestrutura, 2018). Diante 
da pandemia, o governo colombiano anunciou o fornecimento de um volume hídrico mínimo de subsistência - seis metros cúbicos - para a população residencial, garantido por recursos públicos de origem já definida.

A definição clara da fonte de recurso é algo que não foi observado em todos os casos brasileiros em que foi concedida isenção tarifária. Os governos de alguns estados assumiram o pagamento dos usuários isentos, como é o caso da Paraíba (Companhia de Água e Esgoto da Paraíba [Cagepa], 2020), Bahia (Governo da Bahia, 2020) e do Ceará (Companhia de Água e Esgoto do Ceará [Cagece], 2020), de modo a reduzir o impacto sobre as companhias estaduais. Em outros casos, como a companhia paulista - Sabesp - a empresa arcará com a isenção e deverá ser compensada pela redução de despesas e ajustes orçamentários (Sabesp, 2020).

Apesar de as medidas de proteção dos usuários serem meritórias neste momento de crise, há de se ponderar seus possíveis impactos nos médio e longo prazos. A isenção tarifária, bem como a concessão de outros benefícios - por exemplo, dilatação do prazo para o pagamento das faturas e a suspensão da cobrança de multas e juros - irão desequilibrar as contas das prestadoras até que o regulador dê início ao processo de reequilíbrio econômico-financeiro, o que pode vir a acontecer apenas com o fim do período de distanciamento social.

\section{POTENCIAIS IMPACTOS E DESAFIOS DAS MEDIDAS}

Esta seção visa discutir os potenciais impactos sobre (i) prestadores de serviços; (ii) usuários; (iii) reguladores de saneamento em curto, médio e longo prazos, provocados pelo distanciamento social e pelas ações já adotadas pela Administração Pública no que tange aos serviços de abastecimento de água e esgotamento sanitário. Ademais, propõem-se abordagens a serem perseguidas pela Administração Pública deste setor que permitiriam mitigar alguns desses impactos negativos das ações preventivas adotadas.

\subsection{Prestadores de Serviço}

Dois dos efeitos das medidas de distanciamento social impactam diretamente as prestadoras de serviço de saneamento. O primeiro é a desaceleração da economia e o consequente aumento do nível de desemprego; o segundo é a maior permanência da população em suas residências. Como consequência do maior índice de desemprego, espera-se aumento do índice de inadimplência dos usuários, cuja média nacional no ano de 2018 - situação pré-pandemia - correspondia a 6,5\% (MDR, 2018). Ainda que as facilidades de pagamento conferidas por algumas companhias possam vir a suavizar o aumento na inadimplência, nota-se que tal medida não foi adotada em larga escala pelas CESBs - apenas 15\%, conforme Figura 2. Além disso, a suspensão do corte do fornecimento de água por inadimplência pode incentivar o não pagamento da conta pelo usuário, o que terá impactos de maior proporção do que as eventuais facilidades de pagamento promovidas, visto que esta medida foi adotada em escala muito maior entre as companhias estaduais (88\%).

A maior permanência da população nas residências e a simultânea redução da atividade comercial e industrial irão alterar o padrão de consumo de água. Espera-se a redução do consumo de usuários não residenciais (comercial, industrial e público) e, por outro lado, o aumento do consumo residencial. Isto incidirá negativamente na arrecadação das companhias em virtude da estrutura tarifária por

ReVISta de Administração Pública | Rio de Janeiro 54(4):1022-1036, jul. - ago. 2020 
elas praticada. Exemplificativamente, segundo informações disponibilizadas via comunicação com especialista da Agência Reguladora de São Paulo (ARSESP), as economias não residenciais da Sabesp, maior empresa de saneamento do Brasil, representam apenas $8 \%$ do total; já em termos de volume medido, essa representatividade aumenta para cerca de $15 \%$; e em relação à participação no faturamento, sobe para $28 \%$, o que comprova a relevância dessa categoria no faturamento das prestadoras. Até o momento não estão disponíveis informações oficiais quanto ao aumento ou redução da demanda de cada categoria de usuário; desse modo, não é possível, ainda, estimar o impacto na receita da companhia decorrente da alteração no padrão de consumo de água.

Somam-se ao aumento da inadimplência e às alterações nos padrões de consumo as medidas adotadas para garantir a manutenção do serviço: adiamento do reajuste tarifário, isenção tarifária, suspensão da cobrança de multas, dilatação do prazo para o pagamento das faturas, etc. Todas elas implicam redução das entradas no fluxo de caixa das prestadoras. Cabe um olhar mais atento à isenção da tarifa social, medida altamente adotada pelas CESBs (62\%). A tarifa social constitui um arranjo em que o usuário enquadrado na categoria social é subsidiado e, portanto, arca com um custo menor do que ele representa à prestadora. A tarifa social é um benefício concedido à população de baixa renda (categoria social), o que, do ponto de vista econômico-financeiro, representa menor impacto sobre as demais categorias de usuários do que isentá-la do pagamento de qualquer tarifa. Neste último caso, significa que os demais usuários irão dividir entre si os custos totais dos usuários isentos, e não apenas os subsidiarão.

Como resposta aos desafios impostos pela pandemia, muitos dos prestadores optaram por migrar do arranjo de concessão da tarifa social (subsídio) para a isenção da sua cobrança. A representatividade das economias beneficiárias da tarifa social varia substancialmente entre os prestadores de serviços: de pouco mais de 14\%, no caso da Copasa, até cerca de 1\%, no caso da Companhia Catarinense de Água e Saneamento (CASAN), conforme aponta a Associação Brasileira de Agências de Regulação (ABAR, 2018). Tal variação justifica-se, em parte, pelos diferentes critérios adotados pelas prestadoras na concessão dos benefícios sociais aos usuários ${ }^{1}$. Consequentemente, a arrecadação via tarifa social também varia em termos de representatividade na receita operacional de água das CESBs: na Copasa, responde por $9,5 \%$, enquanto na CASAN, por menos de $0,5 \%$ (ABAR, 2018). Estes dados sugerem que o impacto econômico-financeiro da adoção desta medida pode variar bastante a depender da CESB.

Ao mesmo tempo que a arrecadação dos prestadores é negativamente impactada pela pandemia e seus desdobramentos, seus custos operacionais se mantêm ou aumentam, pois, devido à pandemia, gastos extras surgem, tais como: aquisição de equipamentos de proteção para os funcionários, máscaras e álcool em gel. É provável que o impacto negativo decorrente do aumento dos custos operacionais não seja de igual magnitude àquele causado pela redução da arrecadação. De todo modo, ao que tudo indica - até o momento, não há dados públicos disponíveis que quantifiquem os impactos -, haverá desequilíbrio econômico-financeiro das prestadoras de serviço.

No entanto, algumas medidas adotadas pelas CESBs devido à pandemia, se mantidas, têm a possibilidade de reduzir os custos operacionais. Uma delas é a suspensão ou restrição de atendimentos

\footnotetext{
${ }^{1}$ A Copasa concede o direito de pagamento da tarifa social aos usuários de unidades residenciais, inscritos no Cadastro Único para Programas Sociais (CadÚnico), cuja família apresente renda mensal por pessoa igual ou inferior a meio salário mínimo nacional. Já a CASAN concede o benefício para usuários que residem em imóvel de até $70 \mathrm{~m}^{2}$ de área construída para fins residenciais, que não possuam automóvel e cujo rendimento familiar seja igual ou inferior a dois salários mínimos para famílias de até quatro habitantes, ou renda familiar per capita de até 0,5 salário mínimo por habitante.
} 
presenciais, com a consequente disponibilização de canais virtuais para o atendimento dos usuários. Não se pode afirmar que isto de fato ocorrerá, porém, pode-se imaginar que, caso sejam reduzidos os atendimentos presenciais - neste cenário, deve-se atentar para a manutenção da qualidade do serviço prestado aos clientes -, os gastos com aluguéis diminuam e, potencialmente, com pessoal. Esta é uma decisão a ser considerada pelas CESBs e pelos reguladores, especialmente em um cenário póspandemia, que ainda exigirá, no paulatino retorno ao "normal", algumas medidas de distanciamento social até que a população seja vacinada, e no qual os usuários ainda conviverão com reduzida capacidade de pagamento.

Outra possibilidade de redução de custos advém das medidas alternativas de faturamento, como aquela adotada pela Copasa, em que o próprio usuário comunica ao prestador o seu consumo de água. Neste caso, se a medida for mantida após a pandemia, haverá uma potencial redução de custo com pessoal, pois, provavelmente, não será mais necessária a atual quantidade de leituristas. Contudo esta função não se restringe à leitura dos hidrômetros, pois, os leituristas também verificam a conformidade, ou não, destes equipamentos, o que não poderá ser feito pelo usuário.

Quantificar o desequilíbrio econômico-financeiro das prestadoras é de fundamental importância para que o equilíbrio possa ser reestabelecido por ocasião da revisão tarifária das companhias. Mas, antes disso, no curto prazo, essa quantificação permitirá identificar por quanto tempo o capital de giro das prestadoras conseguirá sustentar suas operações. Para pensar em soluções, é necessário primeiramente identificar os impactos financeiros da pandemia; até o momento não foram disponibilizados estudos sobre o assunto. Somente com a identificação dos impactos, os prestadores estarão aptos a pleitear o restabelecimento do equilíbrio econômico-financeiro aos reguladores.

Não se deve pensar que os impactos negativos sobre as prestadoras de saneamento cessarão uma vez que se iniciem os processos de reequilíbrio. Isto porque surgirá o novo desafio de julgar os desequilíbrios que de fato foram causados pela pandemia, momento em que haverá espaço para que os entes reguladores atuem com discricionariedade em suas tomadas de decisão. Na realidade, corre-se o risco da imprevisibilidade das tomadas de decisão, dada a excepcionalidade da situação vivida e a ausência de metodologias já divulgadas que possibilitem dar um tratamento padronizado ao cálculo dos impactos causados pela pandemia.

A falta de metodologias padronizadas é anterior à pandemia, e afeta a regulação do setor de saneamento brasileiro, que é fragmentada pela titularidade municipal dos serviços (Smiderle et al., 2020). Como reflexo da fragmentação regulatória, os reguladores poderão atuar de formas distintas. Uma vez que a reforma do marco legal do saneamento foi recentemente sancionada, instituindo a Lei $\mathrm{n}^{\circ} 14.026 / 20201$, é possível que seja editada alguma diretriz nacional sobre como lidar com os reequilíbrios pleiteados no contexto de pandemia. A Agência Nacional de Águas e Saneamento (ANA) atuará como uma supervisora regulatória, tendo a responsabilidade de editar normas de referência a serem seguidas pelos reguladores.

\subsection{Usuários}

No curto prazo, todas as medidas adotadas pela Administração Pública beneficiam a população, não apenas pela tranquilidade financeira proporcionada aos usuários, em especial os mais vulneráveis, mas, principalmente, pela garantia do acesso à água potável, contribuindo para a proteção contra a doença. Já no médio e longo prazo, esses benefícios passam a ser duvidosos. De um lado porque,

Revista de administração pública | Rio de Janeiro 54(4):1022-1036, jul. - ago. 2020 
uma vez que seja concedido o direito de reequilíbrio econômico-financeiro às prestadoras, as tarifas de água e esgoto - principais meios de sustento do serviço, conforme determina a Lei ${ }^{\circ}$ 11.445/2007 em seu artigo 29 - potencialmente sofrerão aumento. De outro lado, porque os mesmos usuários na posição de contribuintes - terão de arcar, via contribuição fiscal, com a isenção tarifária que, em alguns casos, foi assumida pelos respectivos governos estaduais. Este é o caso de estados como Bahia, Ceará, Mato Grosso do Sul e Paraíba.

Dois efeitos da concessão de subsídios por parte dos governos estaduais merecem destaque. $\mathrm{O}$ primeiro deles é que, dada a velocidade com que a Administração Pública teve de responder aos desafios impostos pela pandemia, pode-se inferir que provavelmente não houve previsão na Lei Orçamentária Anual para o empenho de recursos públicos na concessão desses subsídios. Na prática, o que poderá acontecer é a realocação de recursos e a não cobertura de alguma pauta. O segundo efeito é que, como são os contribuintes que em algum momento arcarão com essa isenção tarifária, é possível que um cidadão pagador de imposto esteja financiando um subsídio, quando ele mesmo não é beneficiado pelo acesso à água. Infelizmente esta é uma situação a ser considerada, visto o déficit ainda existente no atendimento aos serviços de saneamento no país.

\subsection{Reguladores}

No âmbito administrativo, a sustentabilidade financeira das agências reguladoras é garantida por meio da cobrança da taxa de regulação das prestadoras reguladas, geralmente calculada como uma porcentagem do faturamento da empresa com a prestação do serviço. Com isso, é razoável supor que a prevista queda do faturamento das prestadoras de serviço afetará negativamente a arrecadação das agências reguladoras, como em um efeito cascata. Assim, as agências reguladoras deverão prever como lidar com a redução de receita.

Como mencionado, o regulador terá de reestabelecer o equilíbrio econômico-financeiro das prestadoras de serviço em decorrência das medidas adotadas no combate à pandemia. $\mathrm{O}$ primeiro desafio está na interpretação da causa desse desequilíbrio, uma vez que se trata de uma situação nunca antes enfrentada. A Advocacia-Geral da União (AGU) emitiu parecer reconhecendo o direito das concessionárias de infraestrutura de transporte à recomposição do equilíbrio dos seus contratos e caracterizou a pandemia como um evento de "força maior" ("caso fortuito") (Consultoria Jurídica junto ao Ministério da Infraestrutura, 2020). A justificativa para essa interpretação foi de que o evento e as suas consequências não poderiam ter sido previstos pelo prestador. Se esse mesmo entendimento for adotado para o setor de saneamento, e havendo matriz de risco definida em contrato que aloque o risco de força maior ao poder concedente, então o papel do regulador será o de garantir o direito do prestador ao reequilíbrio. Já nos casos em que não há alocação clara deste risco, o regulador deverá atuar com protagonismo na condução de negociação entre as partes. Em ambos os casos, será imprescindível firmar termo aditivo contratual para validar a decisão, seja ela o aumento tarifário ou a extensão do prazo contratual ou mesmo a prorrogação de investimentos, como formas alternativas de evitar aumentos nas tarifas.

Outra dificuldade a ser enfrentada pelos reguladores diz respeito a como separar o desequilíbrio provocado pelo evento de "força maior" daqueles provenientes de outros fatores. Desse modo, tais fatores precisam ser confrontados com a matriz de risco contratual a fim de se julgar se dão ou não ensejo a reequilíbrio econômico-financeiro. Ainda caberá ao regulador identificar, dentro de todo 
esse contexto, o que pode ser atribuído à ineficiência do prestador e, portanto, o que não deve ser remunerado.

A situação de pandemia, devido à gravidade de seus impactos, exige clareza de procedimentos. Por este motivo, cabe ao regulador definir de maneira clara o procedimento que os prestadores deverão seguir para pleitear o reequilíbrio econômico-financeiro no contexto da pandemia. Por exemplo, o regulador pode exigir que o pleito venha acompanhado da declaração de calamidade pública pelo Poder Executivo. O regulador precisará se posicionar por meio de diretrizes, normativos ou mesmo termo aditivo firmado entre poder concedente e prestador, no qual, novamente, o ente regulador terá papel mediador de fundamental importância. Tais diretrizes terão de responder a dúvidas comuns que naturalmente vão surgir nos prestadores. Dúvidas como: os investimentos poderão ser prorrogados? Como manter a qualidade da prestação dos serviços com reduzida arrecadação? Como as não conformidades serão tratadas?

Neste momento, recomenda-se ao regulador cautela ao fiscalizar o atendimento das metas contratuais para a realização de investimentos. Devido às medidas de distanciamento social, algumas obras podem ter sido paralisadas e o regulador tem de tomar conhecimento de toda e qualquer paralisação e talvez considerar, neste momento, a flexibilização de metas. Relativamente aos investimentos, o regulador poderá realinhar os incentivos e redefinir as prioridades. Propõe-se que o regulador, antes de emitir tais diretrizes, conduza uma análise de impacto regulatório em ritmo emergencial, ou seja, em um processo mais ágil do que o de costume, com coleta de dados instantâneos e rápidas análises.

Sugere-se que, enquanto os processos de reequilíbrio não se iniciarem, os reguladores empenhem esforços em definir claramente seus procedimentos e em ouvir o poder concedente e as prestadoras. Além disso, é fundamental que o regulador solicite constantemente das prestadoras reguladas informações sobre redução ou aumento da demanda de água nas diversas categorias de consumo, bem como sobre os preços dos insumos, para que seja possível correlacionar qualquer oscilação nos valores a efeitos da pandemia. Ademais, cabe o acompanhamento das obras paralisadas, identificando o motivo de sua interrupção e sendo realista com relação à viabilidade da sua retomada em curto e médio prazos.

\section{CONSIDERAÇÕES FINAIS}

Segundo orientação da OMS, durante este período de pandemia é fundamental que se garanta à população acesso à água potável como forma de prevenção da COVID-19. Os prestadores de saneamento se viram diante do desafio de garantir a manutenção dos seus serviços para uma população acometida pela retração econômica e, portanto, sem capacidade de pagar pelo serviço. Neste contexto, os atores do setor (titulares dos serviços, prestadores e reguladores) encadearam ações voltadas à proteção de seus funcionários e dos usuários, especialmente os mais vulneráveis economicamente. Para a proteção dos funcionários, a medida preferida pelas companhias estaduais foi a restrição do atendimento presencial nas unidades de atendimento, adotada por $88 \%$ dos estados. Com relação à proteção financeira do usuário, as medidas mais empregadas foram a suspensão do corte por inadimplência (88\%), seguida pela isenção da cobrança da tarifa social (62\%).

Para o prestador de serviço, o impacto no curto prazo é o desequilíbrio econômico-financeiro de suas contas devido aos benefícios concedidos à população, como isenção tarifária, suspensão 
da cobrança de multas, dilatação de prazo para o pagamento das faturas; situação agravada pelo aumento dos custos com a aquisição de equipamentos de proteção dos funcionários e a alteração no padrão do consumo de água, com a redução da demanda de usuários não residenciais. As prestadoras terão de arcar com esse desequilíbrio em suas contas até que o ente regulador conclua o processo de reequilíbrio, o que só deve ocorrer depois da pandemia. Cabe à prestadora quantificar os reais impactos da pandemia e das medidas a ela associadas para que possa fazer seu pleito ao regulador.

Sobre o usuário recairá a conta depois da pandemia, dado que, potencialmente, as tarifas de água e esgoto aumentarão como consequência dos processos de reequilíbrio econômico-financeiro das prestadoras. Ademais, nos estados cujos governos se responsabilizaram pela isenção tarifária conferida aos usuários vulneráveis, os próprios usuários contribuintes, em algum momento, terão de repor os recursos públicos realocados por ocasião da pandemia.

Ao regulador recairá o grande desafio de remediar os impactos causados à prestadora de serviço. O ente regulador será, assim como está sendo durante a pandemia, um ator extremamente importante depois deste período, e para ele são feitas as recomendações deste artigo. Caberá ao ente regulador definir com clareza seus procedimentos ante as prestadoras e o poder concedente para que aquelas saibam como deverão pleitear seus reequilíbrios econômico-financeiros. Recomenda-se que o regulador emita diretrizes e possivelmente firme termos aditivos que prevejam a flexibilização das metas contratuais.

A relação regulador-prestadora, portanto, será mais importante do que nunca neste momento, de modo a diminuir a natural assimetria de informação entre as partes e permitir mais transparência acerca de quais impactos no caixa das companhias são associados, ou não, à pandemia. A boa governança poderá minimizar os impactos futuros sobre os cidadãos brasileiros, ao mesmo tempo usuários dos serviços em questão e pagadores de impostos. 


\section{REFERÊNCIAS}

Agência Reguladora de Serviços Públicos Delegados do Estado de Rondônia. (2020). Agero adverte: empresas concessionárias não podem interromper o fornecimento de água durante 60 dias. Notícias. Porto Velho, RO: Autor. Recuperado de http:// www.rondonia.ro.gov.br/agero-adverte-empresasconcessionarias-nao-podem-interromper-ofornecimento-de-agua-durante-60-dias/

Agência Reguladora do Paraná. (2020). Estado congela por 60 dias tarifas dos serviços regulados. Notícias. Curitiba, PR: Autor. Recuperado de http:// www.agepar.pr.gov.br/modules/noticias/article. php?storyid=256\&tit=Estado-congela-por-60-diastarifas-dos-servicos-regulados

Agência Tocantinense de Saneamento. (2020). Governador determina suspensão de cortes de água e energia. Notícias. Palmas, TO: Autor. Recuperado de https://ats.to.gov.br/noticia/2020/3/25/governadordetermina-suspensao-de-cortes-de-agua-eenergia-/

Associação Brasileira de Agências de Regulação. (2018). Tarifa Social nas companhias estaduais de saneamento básico e o papel da regulação. Brasília, DF: Autor. Recuperado de http://abar.org.br/wpcontent/uploads/2018/12/3.-Estudo-Tarifa-SocialABAR-19-12.pdf

Centro de Estudos de Regulação e Infraestrutura. (2018). Regulação e infraestrutura em busca de uma nova arquitetura. Rio de Janeiro, RJ: Autor. Recuperado de https://ceri.fgv.br/sites/ default/files/publicacoes/2018-10/63_63_regulacaoe-infraestrutura-em-busca-de-uma-novaarquitetura-2018.pdf

Companhia de Água e Esgoto do Ceará. (2020). Famílias beneficiadas: isenção nas contas de água garante serviço essencial durante a pandemia. Notícias. Fortaleza, CE: Autor. Recuperado de https://www.cagece.com.br/comunicacao/noticias/ familias-beneficiadas-isencao-nas-contas-de-aguagarante-servico-essencial-durante-a-pandemia/

Companhia de Água e Esgoto do Paraíba. (2020). Clientes da tarifa social estão isentos de pagamento das contas até junho. Notícias. João Pessoa, PB: Autor. Recuperado de http://www.cagepa.pb.gov.br/maisde-25-mil-familias-nao-pagarao-conta-de-agua-acagepa-ate-o-mes-de-junho/
Companhia de Águas e Esgotos do Rio Grande do Norte. (2020). Caern esclarece que suspensão de cobrança é só da tarifa social. Notícias. Natal, RN: Autor. Recuperado de http://portal.caern.com.br/ Conteudo.asp?TRAN=ITEM\&TARG $=227980 \& A C$ $\mathrm{T}=\& \mathrm{PAGE}=\& \mathrm{PARM}=\& \mathrm{LBL}=\mathrm{NOT} \% \mathrm{CDCIA}$

Companhia de Saneamento Básico do Estado de São Paulo. (2020). Fato Relevante de 19 de março de 2020. São Paulo, SP: Autor. Recuperado de http:// www.sabesp.com.br/CalandraWeb/CalandraRedir ect/?temp $=4 \&$ proj $=$ investidoresnovo\&pub $=$ T\&pa $\mathrm{r}=\mathrm{rel} \& \mathrm{db}=\&$ docidPai $=\mathrm{F} 8 \mathrm{C} 240$ A5E71426DF83257 68C0051BFFF\&docid $=77644$ B 66786 E7BAF03258 531000A2E13

Companhia de Saneamento de Minas Gerais. (2020a). Release de 23 de março de 2020: Prevenção Coronavírus - Saiba como a Copasa está atuando. Notícias - Release. Belo Horizonte, MG: Autor.

Companhia de Saneamento de Minas Gerais. (2020b). Release de 6 de abril de 2020: Prevenção Coronavírus - Orientações para atendimento. Notícias - Release. Belo Horizonte, MG: Autor.

Companhia de Saneamento do Estado do Paraná. (2020). Fato Relevante de 23 de março de 2020. Curitiba, PR: Autor. Recuperado de http://ri.sanepar. com.br/ptb/2306/18627_747418.pdf

Companhia Espírito Santense de Saneamento. (2020). Cesan concede isenção do pagamento das contas de água para 25 mil famílias no Espírito Santo. Notícias. Vitória, ES: Autor. Recuperado de https:// www.cesan.com.br/noticias/cesan-concede-isencaodo-pagamento-das-contas-de-agua-para-25-milfamilias-no-espirito-santo/

Companhia Estadual de Águas e Esgotos do Rio de Janeiro. (2020). Fato relevante do dia 26 de março de 2020. Rio de Janeiro, RJ: Autor. Recuperado de https://www.cedae.com.br/Portals/0/ ri_cedae/comunicados/fato_relevante/Fato $\% 20$ Relevante_20200326.pdf

Companhia Riograndense de Saneamento. (2020). Comunicação do dia 01 de abril de 2020: Companhia adota medidas para minimizar impactos da pandemia no Estado. Porto Alegre, RS: Autor. Recuperado de https://www.corsan.com.br/companhia-adotamedidas-para-minimizar-impactos-da-pandemiano-estado 
Consultoria Jurídica junto ao Ministério da Infraestrutura. (2020). Parecern. 261/2020/CONJURMINFRA/CGU/AGU. Consulta em tese. Covid-19. Reequilíbrio de contratos de concessão. Força Maior. Consultoria Jurídica Junto Ao Ministério da Infraestrutura Gabinete da Consultoria Jurídica. Brasília, DF: Felipe Nogueira Fernandes. Recuperado de https://sapiens.agu.gov.br/documento/406894540

Decreto n. 46.990, de 24 de março de 2020. (2020). Dispõe sobre a suspensão do faturamento de água e esgoto da CEDAE e dá outras providências. Recuperado de https://pge.rj.gov.br/comum/code/ MostrarArquivo.php?C=MTAyMzY\%2C

Deliberação ARSESP n. 978, de 08 de abril de 2020. (2020). Posterga a aplicação dos novos valores das tarifas de água e esgoto, resultantes da Segunda Revisão Tarifária Ordinária da concessionária Saneaqua Mairinque S/A. Recuperado de http://www. arsesp.sp.gov.br/LegislacaoArquivos/ld19782020.pdf

Deliberação ARSESP n. 979, de 09 de abril de 2020. (2020). Autoriza a Companhia de Saneamento Básico do Estado de São Paulo - SABESP a adotar as medidas de que trata o artigo $5^{\circ}$, inciso II, do Decreto $n^{\circ} 64.879$, de 20 de março de 2020, a fim de mitigar as consequências econômicas da pandemia da Covid-19, causada pelo Novo Coronavírus (SARS - CoV-2). Recuperado de http://www.arsesp.sp.gov. br/LegislacaoArquivos/ldl9792020.pdf

Fundo das Nações Unidas para a Infância \& Organização Mundial da Saúde. (2019). Progress on household drinking water, sanitation and hygiene 2000-2017. Special focus on inequalities. New York, NY: United Nations Children's Fund (UNICEF) and World Health Organization (WHO). Recuperado de https://washdata.org/report/jmp-2019-washhouseholds

Governo da Bahia. (2020). Sancionado PL que isenta inscritos na Tarifa Social de pagar conta de água por três meses. Notícias. Salvador, BH: Autor. Recuperado de http://www.bahia.ba.gov.br/noticias/ sancionado-pl-que-isenta-inscritos-na-tarifa-socialde-pagar-conta-de-agua-por-tres-meses

Governo de Goiás. (2020). Caiado garante que Saneago não cortará a água de quem atrasar pagamento. Notícias. Goiânia, GO: Autor. Recuperado de https://www.goias.gov.br/index.php/ servico/95-covid-19/121020-caiado-garante-que- a-saneago-nao-cortara-a-agua-de-quem-atrasarpagamento

Governo de Santa Catarina. (2020). Enfrentamento ao coronavírus, ações do governo do estado de Santa Catarina. Florianópolis, RS: Autor. Recuperado de http://www.coronavirus.sc.gov.br/wp-content/ uploads/2020/04/ACOES-DE-GOVERNO-30DIAS-CORONAVIRUS.pdf

Governo de Sergipe. (2020). Belivaldo suspende cobrança de tarifa social da Deso beneficiando 40 mil sergipanos. Aracaju, SE: Autor. Recuperado de https://www.se.gov.br/noticias/governo/belivaldo_ suspende_cobranca_de_tarifa_social_da_deso_ beneficiando_40_mil_sergipanos

Governo do Amazonas. (2020). Deputados aprovam lei sugerida pela Defensoria que proíbe aumento de preços e cortes de energia e água durante pandemia. Manaus, AM: Autor. Recuperado de http://www.amazonas.am.gov.br/2020/03/ deputados-aprovam-lei-sugerida-pela-defensoriaque-proibe-aumento-de-precos-e-cortes-deenergia-e-agua-durante-pandemia/

Iguá Saneamento. (2020). Iguá suspende a cobrança da tarifa social. São Paulo, SP: Autor. Recuperado de https://www.iguasa.com.br/noticias/igua-suspendea-cobranca-da-tarifa-social

Ministério das Cidades (2018). Publicação VI: Consultoria para ações de assistência técnica, elaboração de estudos e capacitação técnica em regulação e fiscalização de serviços de abastecimento de água e esgotamento sanitário (Projeto Regulação em Saneamento Básico - Regulasan). Brasília, DF: Autor. Recuperado de https://www. integracao.gov.br/images/stories/ArquivosSNSA/ regulasan/11PublicacaoviPropostaDeProgramase AcoesEstrategicasNoAmbitoDeSubsidio.pdf

Ministério do Desenvolvimento Regional. (2018). Base de Dados do Sistema Nacional de Informações sobre Saneamento - Séries Históricas. Brasília, DF: Autor.

NH Consultoria e Planejamento. (1995). Regulação da prestação de serviços de saneamento: análise comparada da legislação internacional (Série Modernização do Setor Saneamento, 6). Brasília, DF: IPEA.

Office of Water. (2020). Letter to all CEOs from Rachel Fletcher on COVID19 water industry response. 
London, UK: Autor. Recuperado de https://www. ofwat.gov.uk/wp-content/uploads/2020/03/Letterto-all-CEOs-from-Rachel-Fletcher-on-COVID19water-industry-response.pdf

Organização Mundial da Saúde. (2020). Responding to community spread of COVID-19 - Interim Guidance. Recuperado de https://apps.who.int/iris/ rest/bitstreams/1271989/retrieve.

Resolução ADASA n. 03, de 26 de março de 2020. (2020). Dispõe sobre o adiamento do Reajuste Tarifário Anual - RTA da Caesb para $1^{\circ}$ de outubro de 2020 e dá outras providências. Brasília, DF: Diário da União. Recuperado de http://www.adasa.df.gov. br/images/storage/legislacao/Res_ADASA/2020/ Resolucao_03_2020.pdf

Resolução ARES-PCJ n. 345, de 23 de março de 2020. (2020). Dispõe sobre as Condições Gerais de Prestação dos Serviços Públicos de Abastecimento de Água Tratada e de Esgotamento Sanitário, no âmbito dos municípios associados à Agência Reguladora PCJ, durante o período de excepcionalidade, emergencial e atípico, para enfrentamento da pandemia de
COVID-19, e dá outras providências. Recuperado de http://www.arespcj.com.br/arquivos/63909_Res olu\%C3\%A7\%C3\%A3o_n\%C2\%BA_345_2020_-Condi\%C3\%A7\%C3\%B5es_Gerais_-_Pandemia_ de_COVID-19.pdf

Smiderle, J., Capodeferro, M., Fernandes, P., Gonçalves, E., \& Dutra, J. (2020). The governance of water and wastewater provision in Brazil: are there clear goals? Network Industries Quarterly, 22(1), 7-11.

Wu, Y., Guo, C., Tang, L., Hong, Z., Zhou, J., Dong, X., ... Huang, X. (2020). Prolonged presence of SARS-CoV-2 viral RNA in faecal samples. The Lancet Gastroenterology \& Hepatology, 5(5), 434435. Recuperado de https://doi.org/10.1016/S24681253(20)30083-2

Yeo, C., Kaushal, S., \& Yeo, D. (2020). Enteric involvement of coronaviruses: is faecal-oral transmission of SARS-CoV-2 possible? The Lancet Gastroenterology \& Hepatology, 5(4), 335-337. Recuperado de https://doi.org/10.1016/S24681253(20)30048-0

\section{Morganna Werneck Capodeferro}

https://orcid.org/0000-0002-5617-5673

Pesquisadora no Centro de Estudos em Regulação e Infraestrutura da Fundação Getulio Vargas (FGV CERI); Mestranda em Engenharia Civil no Programa de Engenharia Civil (PEC/COPPE) da Universidade Federal do Rio de Janeiro (UFRJ). E-mail: morganna@poli.ufrj.br

\section{Juliana Jerônimo Smiderle}

https://orcid.org/0000-0003-3319-7359

Pesquisadora no Centro de Estudos em Regulação e Infraestrutura da Fundação Getulio Vargas (FGV CERI); Mestranda em Engenharia Ambiental no Programa de Engenharia Ambiental (PEA) da Universidade Federal do Rio de Janeiro (UFRJ). E-mail: julianasmiderle@poli.ufrj.br 